\title{
The Disclosure of Life Experience And Its Expression in Cultural Studies Perspective
}

\author{
Dwi Retnani Srinarwati \\ Faculty of Teaching and Education, PGRI Adi Buana University, Surabaya, Indonesia
}

\begin{abstract}
One of the key concepts of cultural studies in dealing with "living culture" is the experience and how to articulate it. The articulation of an experience must avoid pure meaning and the addition of excessive analysis. The pattern of interaction, lifestyle, and mindset observed will bring the ethnographer at the correct level of articulation. In research, cultural studies develop ethnographic methods. Ethnography is a form of socio-cultural research characterized by an in-depth study of the diversity of socio-cultural phenomena of a society. The study was conducted using primary data collection with interview guidelines; research in one or more cases in depth and comparability; data analysis through the interpretation of the function and meaning of thought and action, resulting in the description and analysis verbally. Reality shows that ethnographs often express the experience of "large groups" and reveal less "disadvantaged" parties. Finally a new approach to the research of "new ethnography" is proposed that aims at developing a way of learning and writing that allows the ethnographer to more accurately understand and reveal and articulate the reality of others' lives. New ethnographic practices are often characterized by various strategies, such as collaboration, self-reflexivity, and polvocality. However, coming to its logical conclusion, the new ethnographic search to become a reality for the different realities of life makes one unable to judge between them.
\end{abstract}

Keywords: cultural studies; life; experience articulation; ethnography

\section{INTRODUCTION}

Ethnography is an analysis that describes a society based on field research as data in research. Ethnography presents data that are valid and essential for all research on humans. 
Ethnography is recognized as an appropriate method of analysis to describe a comparative study of society in a herd or comparison of sample societies from around the world. Therefore, ethnographic data about each community is needed for the sample being studied (Parker, 2005:36).

Ethnography is referred to as the observation involved by emphasizing the logic of the invention (logic of discovery), a process aimed at suggesting concepts or constructing a theory based on man's actual reality. Ethnography emphasizes the exploration of the nature of a particular social phenomenon, rather than testing the hypothesis of the phenomenon. Data analysis involves direct interpretation of the meaning and function of human action (Stewart, 1998:25).

For theoretical attempts, ethnographies whose material is collected on the basis of a first-hand and long-term observation provide for a researcher a rich description of the broadest phenomenon of scope. Thus ethnography can encourage thinking about how the connection between different aspects of a culture and also how it relates to the various facets of the natural world (Stewart, 1998:28). Time on the field ethnographers have the opportunity to be able to know the full context of the society's habits by asking about these habits to the citizens and by observing the symptoms that seem to relate to them (Flick, 2007:89). Everyone has an appreciation for an event in their different lives. The difference is due to the different backgrounds brought by each person. Experiences and events can be or even form a culture that is attached to an area and has its own characteristics (Gray, 2003:13).

This characteristic then forms an identity in life. A person's social identity is formed through a social process so as to distinguish it from others. These social characteristics are often not realized by the owner of the identity even though it has become part of the habit in his life. Habit itself is a cultural product that was originally cultivated or created consciously to meet the needs of one's life. The process of being ordinary is not a single process and individual, but done collectively and massively so that people feel that something is done as part of the needs of life to be the same or in accordance with the community in general (Turner, 2000).

Meanwhile, one of the key concepts that is important in cultural studies, especially in addressing the "life culture", the experience and how to articulate it. Therefore, this paper aims: First, explaining why presenting experience becomes an important task of cultural 
studies, ie rebuilding the methodological significance of presenting a common project experience cultural studies; Second, examine the implications of the research methodology on the fact that although experience is common in research, yet the specific experience faced by humans is always different and individual, as we gain meaning and meaning from experience.

\section{REVIEW OF LITERATURE}

\subsection{Human Life Experience and Cultural Studies Development}

Experience is very important in cultural studies. The importance of the concept of experience in cultural studies departs from the emergence of tension and disagreement about what the role of experience in understanding the social world. The methodological significance of experience as a category is discussed in relation to (1) cultural politics and the work of cultural studies in promoting cultural democratization; and (2) researcher relationships and research, and between evidence and analysis. Experience is approached as a source of vital analysis that always requires interrogation. (Pickering, 2008:39).

One characteristic of cultural studies is to focus on the subjective dimensions of social relationships, how certain social arrangements and configurations are lived and understood, thereby highlighting complex intersections between the public culture and personal subjectivity and possible transformative potentials. It is important to feel about who we are or may be who we are and experience - not only what is experienced but also how it is articulated, understood, drawn and shared with others - hence it must be claimed to be important for the changing of identity and the changing conception of the social world that is lived. Kearney (2003:42) has recently observed that 'any consideration of the way individuals engage in the process of creating their identity by constantly reflecting on their life experiences, is largely lost from current research'. Understanding any experience, selfexperience or others, refers to conceptual and theoretical ideas as well as carefully applying methods to bring out and help bring about the experience story of the social world. The use of methods provides guidance on generating data on social and cultural experiences, how they are confirmed and articulated in accordance with procedures and principles, and theories are used to provide a framework for analyzing the experiences and forms it expresses. Bringing 
experience as a process and product is also very important to inform about how the social world is entered and understood.

As described above, experience is a category, encompassing routine activities and the usual events, events, encounters, and responses to what happens to a person, prominently, acting as the pinnacle of a particular process or the deposition of certain feelings, perceptions, or thoughts. In achieving excellence in this way, this extraordinary experience is free from underdevelopment and progress in life, giving new meaning to what has been experienced or will be experienced in a way that is more than habitual, may make us realize that this is what the poet or novelist is meant to be in certain parts of which we have not yet fully understood. The difference here is between experience in his trademark habits and experience that creates increased perceptual or intellectual passion and seems to provide an important quality of experience which further remains the key to the way in which self-understanding and the shifting patterns of life are concerned. As Negus and Pickering (2004) suggest, there is an aspect of duality in experience and will appear in a detailed discussion of the relationship between experience, creativity, and cultural value.

Therefore, the experience is structured around the expectation and realization of hope in a direct way relevant to what it wants to get from research. If research and methods are used only to reassure expectations, then little can be achieved. Just like our daily experience, much of what we do in researching is a matter of routine. The surprising elements in the study can not be separated from the more general parts that point to and away from them, but it is important to make the research a valuable experience.

Furthermore, according to McRobbie (1997), experience is something that can be experienced by everyone, but no one can define the equation appropriately. McRobbie also said that experience involves representation in a disciplined, skillful form, manifestation of action or behavior that requires a distinctive way of looking at the world (Gray, 2003: 13). Experience involves not only the subject, but also of the object and the supporting factors and the viewpoint of the world that is laid out in life. From these statements, it can be outlined that an experience is the result of what representation a person experiences in a subjective memoir that has meaning and function in it. This experience can form a social or even cultural behavior in a society. 
When learning culture, the most important thing is to "see" what people actually do from different cultures. Cultural performance involves the manipulation of various media that may be experienced by the eyes, ears, nose, tongue, and touch. Public performances are like social dramas, where groups unite and their ideas become a distinctive culture. Hall (1997) notes that culture and social tend to follow certain processes. The first stage is the establishment of rules, then the meaning of togetherness, the act of violation or threat to public order. Next comes the second stage, the crisis, when members of society are anxious and take a stand on the various sides of the problem caused by the offense. In the third stage, redressive or repair procedures, members of the culture perform performance that can correct the offense. The fourth stage, reintegration, or restoration of peace. The circumstances of the experience of a social behavior will affect the culture that will be formed later.

In studying the culture, many things are presented in the study, such as how research can include historical elements of the culture studied. Culture itself is believed to be one of the complicated studies. Discussion of human social science is always integrated in practical knowledge, but also contains a complex level of understanding. Therefore, it takes a proper method to deepen the human culture.

Human life experiences affect human knowledge in viewing cultures and interacting with different environments. The process of seeing or paying attention to this is then called the introduction of social studies. One is more concerned that the experience experienced by every condition prevents him from thinking conventionally (Gray, 2003: 26-27). At some point, experience believed to be the foundation for cultural studies, remains a debate. This is attributed to the importance of a more extensive discussion of the experience itself. Not all experiences will become cultures, because the relevance and significance of the "experience" in question must really have meaning and function, not just stories. Saukko (2003) states that cultural knowledge is not something that can be visible in real, but hidden from view, but plays a very important role for humans in determining their behavior. Cultural manifestations are objects created by humans as cultured beings, in the form of behaviors and objects of a real nature, such as patterns of historical and experiential behavior, language, tools of life, social organization, religion, art, others, all of which are intended to assist humans in conducting community life. 
From the experience will create an individual way to engage in the process of recreating his identity. By continually reflecting on life experiences, one will discover the aesthetics of the importance of social life. Nowadays, research associated with one's experience begins to disappear from research. This is because, many researchers consider the process of research experience on cultural studies in the social world is still unclear, superficial, and inadequate. In addition, experiential research shows a non-linear relationship with cultural studies, and is judged to be a contradiction between experience and cultural form, as well as between experience and social identity.

Although still a debate, but the existence of human experience in cultural studies is not necessarily eliminated just like that. Its existence is still used, it only needs reconception and additional data as well as measurable and valid evidence. Experience only arguments is not a proof of research, so it can not be used as a foundation of cultural studies and social sciences. Another thing that needs attention is that experience is never pure or transparent. If experience will be used to provide evidence and to gain insight into everyday culture in a social life, or be used to inform the practice of research and analyze it, the way it is presented must come out of the raw data (in this case, the direct story of the participant without reconception repeated from the researcher).

Any experience shared by participants should be explored, should be interpreted with caution and criticality because one's experience in a social life is not equivalent to what happens to the researcher. Experience is just like what someone does from what happens to that person. Not infrequently there are participants who manipulate the experience that occurs because sometimes something happens not as desired, so the end result will not be linear, while researchers certainly do not know.

At some level, experience in social life can not be avoided, events that occur that form an aesthetic, history, and culture will define the identity of the community or community. There is no absolute definition of this category, which means that a researcher should think about it in general and specific terms or events from sources outside the community before asking questions to participants. Thus, researchers get information first and use it to develop knowledge about social life in places and situations, periods, and other historical formations in the community under study.

\subsection{Management of Human Experience}


To deal with "living culture", bringing experience and articulating it into an important ethnographic task in cultural studies. Ethnography is a study that aims to describe and analyze culture, by understanding the views (knowledge) and its relation to daily life (behavior) in order to get a picture of the "world" of the society under study. Saukko (2003: 40) explains that the description of a group is related to the dominance of behavior "reject" circumstances that are not in accordance with its identity. This means that each group's behavior has a "deviation" rule that can be articulated in the rejection behavior of other cultures that are not hers.

As noted above, that an ethnographer is essential to understanding any experience, selfexperience or others, refers to conceptual and theoretical ideas and carefully applying methods to bring about and help bring about the experience story of the social world. The use of methods provides guidance on generating data on social and cultural experiences, how they are confirmed and articulated in accordance with procedures and principles, and theories are used to provide a framework for analyzing the experiences and forms it expresses. Bringing experience as a process and product is also very important in informing us of how the social world is entered and understood.

Furthermore, narrative articulation becomes very important and it should be emphasized that experience only reaches meaning when framed in a communicative form. In such form, it enters into social exchange and cultural circulation. Experience does not achieve meaning forever. Even in the first movement to the communicative form, there is an important difference between experience and how it is framed in words, pictures, music or cues. Thus, this altered category produces rules and deviations at one and the same time, for it must also be recognized that the experience and subjectivity through which it lives and is told is determined not only by the language and discourse in which they attain expression. One of the reasons why experience is always regarded as a category is that it is not fully covered in language and narrative: 'Any attempt to transmit the vibrations and experience of life into the language loses something important to it' (Magee, 2003: 286). Furthermore, Pickering (2008) states that experience - not only what is experienced, but also how it is articulated, understood, portrayed and shared with others - because it is important to change.

The articulation theory proposed by Hall (1997) is one theory that can be used to understand social formations and is very effective in avoiding the reduction of understanding 
in viewing the formations. The articulation theory explains that the meaning of a cultural phenomenon is not an independent process that occurs "the result" of one cause (consumption occurs due to production or otherwise) but is a dialogical relation within a structure built by a particular framework including culture.

Further, Gray (2003) argues that in order for an ethnographic approach to articulate human experience, the relationship between situations and mediation must be interactive. That is, every experience should be focused on the whole how society defines the local world around it and how people interpret the differences, backgrounds, intercorrelations to cultural assimilation situations that occur in a surrounding social group.

Ethnography is a form of socio-cultural research characterized by an in-depth study of the diversity of socio-cultural phenomena of a society (Stewart 1998: 5). Research using primary data collection with interview guidelines; research in one or more cases in depth and comparability; data analysis through the interpretation of the function and meaning of thought and action, resulting in the description and analysis verbally.

Ancient ethnography, more concerned with the life of the present, namely the way of life of society and the existence of self-reflexivity rules, meaning researchers can not affect the results of direct observation made with participants. Although it is an old theory, it is still a debate, the article if the researcher or ethnographer can not be in research, then the articulation of experience is not systematic (Saukko, 2003: 62). While modern ethnography is more concerned with the dominance of rejection behavior that presents a new social structure in society, where every habit of small groups is measured and retold holistically.

\section{DISCUSSION}

\subsection{Ethnography in Cultural Studies Research}

Language, ethnography means the portrait of a group or society. Ethnographic research is known as a practice that specifically focuses on group behavior or individuals (Saukko, 2003: 44). Ethnography is a social research method that depends entirely on close observation of the researcher, so that the ethnographer needs to equip itself with language, cultural, and in-depth knowledge of the research area, and the use of methods appropriate to the research objectives. Field research in the context of ethnography means that researchers capture data at 
the locations where participants and cultural patterns are researched. The ethnographer captures the data by staying with the participants to observe how the patterns of life they use.

All concepts are needed to analyze the processes of societal and cultural shifts, including the field of anthropological research, cultural studies and sociology called social dynamics. In order to perform the three types of research, ethnography method is needed. To explore and understand the life style of a society, a researcher can use ethnographic studies as a reliable research method. However, it is equally important that an ethnographer must first know the group demographic data under study, ie data on population, detailed in the number of women and the number of men, and as much as possible according to age levels, data on birth rates and mortality rates, as well as data on people moving in and out of the territory. Thus, it can be described as much detail as possible the life of participants, including the culture formed in the region.

Ethnography is a research method used for sociological, anthropological, and cultural studies, but all three have different scales and focus in expressing human experience. There are several ethnographic differences in sociological research, anthropology and cultural studies. This can be explained by Gray (2003: 15-17) as follows:

\section{a. Scale and Extent}

In sociological studies, ethnographic methods are used to express the extent of social populations, which will be associated with more specific samples, which means only selected samples can represent the study. Meanwhile, anthropology is more about movements, dimensions, changes and forms of social existence. Anthropology is not broader than sociological studies, but a little deeper in social life. Then, cultural studies, more exploratory on the identity of social relationships, as well as the meaning and cultural significance that is formed. The sample size is not a major concern in cultural studies.

\section{b. Depth and Duration}

Anthropological researchers have criticized the study of cultural studies that did not engage quite closely with the participants. This, of course, affects the value and significance of the participants' personalities. Anthropological observations do exist in the relationship of participants to culture, while cultural studies are more to the lives of participants involved in shaping their social culture. Duration of anthropological research is longer because it leads more to personal participants. Meanwhile, sociology is more specific, almost every 
sociologist's study is so limited that it does not spread to other studies that interfere with the analysis. So the duration of research sociology more rigid compared with anthropology and cultural studies.

Furthermore, ethnography in the terminology of the discipline of cultural studies presents a critical form of cultural definition which leads to "the complex everyday world we all encounter and through which all moves" (Ellemers, Spears, \& Doosje, 2002). Cultural studies are both antidisciplinary and multidisciplinary. It is said to be antidisciplinary because the way its investigation does not follow the standard rules as applied to other disciplines. It's called multidisciplinary because it covers a lot of things, contains a variety of competing perspectives. In the academic area, cultural studies study culture as a meaning practice in the context of social power. With an eclectic method, cultural studies emphasize the positionality of all knowledge, including itself, that revolves around key ideas such as culture, meaning practice, representation, discourse, power, articulation, text, reader, and consumption.

Cultural studies is a study of various patterns of human behavior both ideologically, politically, economically, socially, and culturally with all its complex aspects. With the complexity encountered, cultural studies move from an understanding of the interdisciplinary or posd disciplinary questions field that seeks to explore the production and inculcation (cultivation) of culture or meaning in each human behavior. Therefore, definitively, cultural studies then become not having a firm and standard reference, and are often said to be only language games. Cultural studies is a discourse formation, a set of ideas, images and practices that underlie conversations about or behavior associated with a particular topic, social activity, and institutional site. That is, cultural studies talk about objects, and create coherence between concepts, ideas, and concerns that include articulation, culture, discourse, ideology, identity, pop culture, power, representation, and text. The basis of his study, cultural studies freely take from the disciplines of social sciences and all branches of the humanities and the arts.

In relation to the notion of culture, cultural studies develop a cultural sense in a new meaning than in the past. A prominent feature is the view that culture is studied as an integral part of power and dominative relations in society, especially capitalist society which is the main study in the cultural studies. Culture is shaped by practice and meaning for everyone as they live their lives. These meanings and practices arise from arenas that are not made by 
themselves, even if they struggle to creatively build lives. Culture does not expose the material conditions of life, on the contrary, whatever the purpose of cultural practice, its incontrovertible means of production is always material. (Raymond Williams, 1981: 87). Thus, the meaning of living culture should be explored within the context of their production terms so that it becomes a cultural form as the "whole of life".

Referring to Hall (1997), culture is also defined as the habits and rituals that govern and determine our social relationships based on everyday life as well as those texts - literature, music, art and through such customs and rituals the social and natural world is displayed back or marked-interpreted - in a way that conforms to a particular convention. Hall defines the concept of culture using a universal approach, that is, the concept of culture refers to shared meanings. This meaning is centered on everyday meaning: value, material / symbolic objects, norms.

The ethnographic study of its nature includes experience in daily life (culture), such as the texts, practices, and meaning of all people in living their lives in groups. This is in line with what William said that the important thing is to think about how we can understand the ways in which culture is produced in and through everyday life, what Raymond Williams calls 'living culture' (Williams 1981: 11 ). Furthermore, Hall (1997) suggests that culture be investigated in several terms. First, the institutions that produce art and culture. Second, educational formations, movements, and factions in the production of culture. Third, the forms of production, including all its manifestations. Fourth, the identification and forms of culture, including the specificity of cultural products, aesthetic purposes. Fifth, its reproduction in the course of space and time; and Sixth, how to organize it.

Meanwhile, Saukko (2003: 83-92) offers several ways of conducting ethnographic research, namely by narrative analysis, domain analysis, social approach, and dialogue. The ways offered by Saukko are related to reducing the potential for bias in ethnographs. Further described briefly as follows: (1) Narrative analysis, which is related to retelling by the dialogue text of participants; (2) Analysis of domain inquiry units into a larger cultural knowledge called a domain. Researchers will look for cultural symbols that belong to a larger category (domain) based on similarities. (3) The social approach is related to the in-depth introduction and exploration of the existing groups within a society; and (4) Dialogue is a 
critical analysis approach to participants through questioning that is equivalent to giving little influence to the participant's statement.

In cultural studies, ethnographic methods will be very useful for stabilizing research. The pattern of interaction, lifestyle and mindset observed will bring the ethnographer at the proper articulating level. Dialogue, narrative analysis, social approach, to the domain analysis offered can also assist the researcher in defining the condition of the group of participants. The articulation of an experience at its core should avoid pure meaning and the addition of excessive analysis. Cultural studies relate to all parties, institutions and systems of classification where embedded values, beliefs, competencies, routines of life and forms of behavioral habits (Gray, 2003: 31).

\subsection{New Ethnography as an Alternative Solution}

There are serious allegations that social and cultural research has illustrated the people, especially those who have lost rights, such as working-class youth or non-Westerners, in an unfair way to their feelings of reality (eg Clifford and Marcus, 1986). Therefore, a new alternative emerged to address the problem, namely "new ethnography". The hallmark of new ethnography is its commitment to 'more right' to the reality of another's life. Thus, new ethnography usually challenges concepts - such as 'resistance' - that social research uses to categorize or label individuals.

The goal of new ethnographic research is to develop a way of learning and writing method that allows researchers to more accurately express the reality of the lives of others. Thus, new ethnographic practices are often characterized by various strategies, namely: First, collaboration, which aims to improve the articulation of experiences expressed by participants; Second, self-reflexivity, which aims to raise the scientist's consciousness of the social and cultural notions that mediate his understanding of a world that may be radically different from himself; Thirdly, polvocality is drawing attention to the fact that the reality of life is overwhelming, and to do so, in order to be fair it is necessary to listen to many voices or perspectives. (Saukko, 2003: 72-73). However, coming to its logical conclusion, the new ethnographic search to become a reality for the different realities of life makes one unable to judge between them. So, to avoid some kind of unreasonable pluralism, who would argue that sound is as good as others, one needs to evaluate the reality of any life to the social context. 
The reason for the use of new ethnography is to make ethnographic disclosures more accurate and replicable than they were in the past. To achieve this goal, ethnographs must seek to reproduce the cultural reality of the views, arrangements, and appreciation of cultural societies (Stewart, 1998: 7). This means that the exposure of a particular culture must be expressed in terms of conceptual rules, categories, codes, and cognitive rules of participants and not because of the conceptual categories derived from the education of researchers.

Participant cognitive rules are closely related to the experience of the participants. In this case, cognitive rules mean how participants can share their experiences systematically. At the social level, as explained earlier, that experience is just as an introduction. A person's life does not necessarily have a significant effect on his community. Because the experience is always independent and different for each human being.

It could be the experience that is told has a mild impact, but the experience described can also be the opposite (Ellemers, Spears, \& Doosje, 2002). Therefore, any experience gained from participants can not be used as data directly. Thus, ideal ethnography must include all the rules, rules, and categories that the community must know in order to understand how to act appropriately in the various social situations it faces in everyday life. Only in this way the impact of inequalities arising from the theoretical preferences and ethnographic cultural biases can be neutralized, and a description reflecting the reality of "real" culture can be more credible. Pickering (2008: 22) states that contradicting some ethnographic opinions, which suggest that group representatives in ethnographic studies are actually understandable, because each community in the social consciously or not has a stereotype "disease" of a group. The growing stereotype shows that group differences form a strong culture within the group, and this can also be called experience. Experience in social behavior is the atmosphere of interdependence which is a must to ensure the existence of human being which is then stored as a learning in berkehidupan. As proof that human learning can be fulfilled as a personal need, one will learn how to treat the time or culture that has been formed as a result of an event that has been experienced by human or society. Pickering (2008: 24) also states that not only differentiation can distinguish the experience, but also how an ethnographer seeks to experience the same experience with participants. There is a significant difference between the first subject (who has direct experience) with the second 
subject (who only listens to the experiences of others). The researcher or ethnographer can not be said to exist if it is not or has not become a unity as the first subject.

The existence of bonds of interdependence between one person with another. This means that human survival takes place in an atmosphere of mutual support in togetherness. For that, people are required to work together, mutual respect, not disturbing the rights of others, tolerant in community life in shaping the whole culture. The social experience created appears in the pattern of interpersonal responses expressed by interpersonal relationships. Social experience is also synonymous with one's reaction to others. Social experience is indicated by feelings, actions, beliefs, memories, or respect for others (Turner, 2000). Social experience is a relative learning trait to respond to others in different ways. Since birth, humans need to associate with others to fulfill their social needs. In the development toward maturity, social interaction among humans can realize their lives individually. This is because if there is no reciprocal of social interaction then man can not realize his potential as a whole person as a result of social interaction (Sprears, 2011).

These potentials can initially be known from their daily behavior. At the time of socializing it is shown is social behavior, which then form a group experience (Turner, 2000). The formation of social experience is influenced by various factors, both internal and external. In the external aspect, the social situation plays an important role. Social situation is defined as each situation where there is a mutual relationship between people with each other. In other words every situation that causes social interaction can form a social experience.

\section{CONCLUSION}

Based on the various statements above, it can be concluded that:

1. Ethnography in the study of cultural studies is used to describe social life as a whole about a group or culture in the group. One of the key concepts of cultural studies in dealing with "living culture" is experience. The use of human experience is a method of obtaining ethnographic desirable data.

2. The human experience, it is generally agreed to be the data, but it takes skill of the ethnographer for critical thinking, view and examine carefully careful about human experience that can uncover pengalamanan is processed into a systematic review. 
3. In cultural studies, ethnographic methods will be very useful for stabilizing research. The pattern of interaction, lifestyle and mindset observed will bring the ethnographer at the proper articulating level. Dialogue, narrative analysis, social approach, to the domain analysis offered can also assist the researcher in defining the condition of the group of participants. The articulation of an experience at its core should avoid pure meaning and the addition of excessive analysis.

4. In articulating human experience, an ethnographer must be able to reconcept or redefine precisely to the human experience described by the participant, to obtain maximum proportionality of data. The use of methods provides guidance on generating data on social and cultural experiences, how they are confirmed and articulated in accordance with procedures and principles, and theories are used to provide a framework for analyzing the experiences and forms it expresses.

5. 'New ethnography', appears to address allegations of sociocultural research partisanship to certain groups, especially those who have lost rights. Therefore, new ethnography comes with its commitment to 'more right' to the reality of another's life. The goal of new ethnographic research is to develop a way of learning and writing method that allows researchers to more accurately express the reality of the lives of others. Thus, new ethnographic practices are often characterized by strategies: first: collaboration, aimed at improving the articulation of experiences expressed by participants; Second, selfreflexivity, which aims to raise the scientist's consciousness of the social and cultural notions that mediate his understanding of a world that may be radically different from himself; Thirdly, polvocality is drawing attention to the fact that the reality of life is overwhelming, and to do so, in order to be fair it needs to listen to many voices or perspectives.

\section{REFERENCES}

Clifford, J. and Marcus, G.E. (eds) (1986). Writing Culture: The Poetics and Politics of Ethnography. Berkeley, CA: University of California Press.

Ellemers, N., Spears, R., \& Doosje, B. (2002). Self and Social Identity. Annual Rev. Psychology Vol. 53, 161-186.

Flick, U. (2007). Designing Qualitative Research. London: SAGE Publication. 
Gray, Ann. (2003). Research Practice for Cultural Studies: Ethnographic Methods and Lived Cultures. California: SAGE Publications.

Gupta, A. and Ferguson, J. (eds.) (1997) Culture, Power, Place: Explorations in Critical Anthropology. Durham, NC: Duke University Press.

Hall, S. (1996). Representation: Cultural Representations and Signifying Practices. London: SAGE Publication. (1997). The Circuit of Culture.

Johnson, R. (1997). 'Reinventing cultural studies: remembering for the best version', in E. Long, From Sociology to Cultural Studies: New Perspectives. Malden, MA: Blackwell.

Kearney, C. (2003) The Monkey's Mask, Stoke on Trent, UK and Sterling, USA: Trentham Books.

McRobbie, A. (ed.) (1997) Back to Reality? Social Experience and Cultural Studies. Manchester: Manchester University Press.

Magee, B. (2003) Clouds of Glory: A Hoxton Childhood, London: Jonathan Cape.

Morris, M. (1997). “A question of cultural studies”, in A. McRobbie (ed.), Back to Reality? Social Experience and Cultural Studies. Manchester: Manchester University Press.

Negus, K. and Pickering, M. (2004) Creativity, Communication and Cultural Value. London, Thousand Oaks, New Delhi: Sage.

Parker, I. (2005). Qualitive Psychology: Introducing Radical Research. New York: Open University Press.

Pickering, Michael. (2008). Research Methods for Cultural Studies. Edinburgh: Endinburgh University Press.

Probyn, E. (1993) Sexing the Self: Gendered Positions in Cultural Studies. NewYork: Routledge.

Saukko, Paula. (2003). Doing Research in Cultural Studies: An Introduction to Classical and New Methodological Approaches. London: SAGE Publication.

Sprears, R. (2011). Group Identities: The Social Identity Perspective. In S. S. al, Handbook of Identity Theory and Research (pp. 201-223). London: Springer Science+Business Media.

Stewart, A. (1998). The Ethnographer's Method: Qualitative Research Methods Series Volume 46. California: SAGE Publications Inc. 
Turner, J. (2000). Social Categorization and the self-concept: A social cognitive theory of group behavior. In E. Lawler, Advance in Group Processes Vol. 2 (pp. 77-122). Greenwich: JAI Press.

Williams. R. (1981). Culture. Glasgow: Collins. 